\title{
DYNAMIC REGIME OF IGNITION OF SOLID PROPELLANT
}

\author{
Nikolay Zolotorev ${ }^{1, *}$, Valeriy Kuznetsov ${ }^{1}$, and Eugene Maslov ${ }^{2}$ \\ ${ }^{1}$ National Research Tomsk State University, 634050 Tomsk, Russia \\ ${ }^{2}$ National Research Tomsk Polytechnic University, 634050 Tomsk, Russia
}

\begin{abstract}
This article presents a dynamic regime of exposure of the radiant flux on the sample of gun-cotton. Obtained time the ignition of gun-cotton in the heating conditions of increasing heat flux in the range from $0.2 \mathrm{~W} / \mathrm{cm}^{2}$ to $22 \mathrm{~W} / \mathrm{cm}^{2}$. A comparison of the delay times of the ignition when heated variable and constant heat flux.
\end{abstract}

\section{Introduction}

Studying the process of ignition of solid fuels is usually carried out under simple conditions of added heat: constant temperature or heat flux on the surface in so-called "static regime" $[1-5]$. In real conditions, the ignition is carried out at variable, time-dependent values of heat flux. The formation of the warm layer in this case is carried out in complicated dynamic conditions and significantly depends on the regime of change in heat flux during the period of heating of the studied sample [1].

The analysis of dynamic regimes in thermal ignition theory held by A. G. Merzhanov with employees [1], that showed that the characteristics of the ignition process depend on the type of the external heat flux. With increasing flow the influence of kinetic parameters on the ignition timing is smaller than in the case of constant or decreasing heat flux with time. Experimental study of this phenomenon is quite difficult in technical execution. In the available literature the amount of information experimental data are limited [5].

In the theory of solid-phase ignition occurs at the moment when to the velocity of heat generation in the zone of chemical reaction compares heat sink. With history of determines heat the amount of heat that must be expended to carry out fuel ignition. Characteristics of dynamic regimes of ignition are of practical importance in the use of energy sources with the specified content

Gun-cotton was chosen as model of a solid fuel since it is most studied substance with known kinetic and heat physical characteristics [2]. Delayed times of ignition of gun-cotton in the heating conditions of increasing heat flux in the range from $0.2 \mathrm{~W} / \mathrm{cm}^{2}$ to $22 \mathrm{~W} / \mathrm{cm}^{2}$ are obtained.

\footnotetext{
* Corresponding author: nikzolotorev@mail.ru
} 


\section{The methodology of the experiments}

The experiments were carried out using an optical furnace Uran-1 (fig. 1). The emitter consists of elliptical mirror and hid xenon lamp type DKsR-10000 rated thermal input of 10 $\mathrm{kW}$. [6].

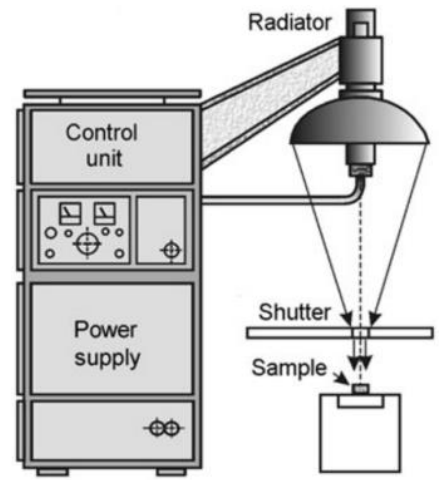

Fig. 1. Installation diagram "Uran-1".

Influence of variable heat flux on the delay time of ignition of gun-cotton in air at atmospheric pressure is studied. The diameter and height of samples are $10 \mathrm{~mm}$, the density is equal to $1.45 \mathrm{~g} / \mathrm{cm}^{2}$. The ignition is determined by the appearance of the flame at the sample surface and recorded by a photoelectric method. Dynamic regime heat flux was provided by moving the test sample during its heating heat flux along the optical axis of the elliptic reflector, the installation of "Uran-1". For this purpose electromechanical device was used that moves the sample at a speed of $4.75 \mathrm{~cm} / \mathrm{s}$. The rate of change of the heat flux was determined by the speed of movement of the sample. The measurement error of the heat flux does not exceed $10 \%$. With the speed of movement of the sample along the optical axis there is a possibility to go from fixed distances to time and to determine the dynamics of the heat flux in this experiment.

\section{Experimental results}

In the regime of increasing the heat flux, we performed a series of experiments that differed by the rate of change of heat flux density in the process of ignition of gun-cotton. A comparison of the characteristics of ignition of gun-cotton obtained with increasing heat flux with the experimental data under constant flow [2] is shown in fig. 2.

From graphs in fig. 2 it is seen that in the studied range $q$ delay time of ignition of guncotton with increasing heat flux with an average value of $q$ is smaller than at a constant heat flux $q_{0}$. With increasing density of the heat flux, difference according to the delay time of ignition decreases and asymptotically tends to zero when $q>8 \mathrm{~W} / \mathrm{cm}^{2}$. The dependence of the amount of thermal energy $Q$ obtained by means of gun-cotton during the period from induction of the heat flux during heating of constant $q_{0}(1)$ and increasing $q$ (2) heat flux is show in fig. 3 . 


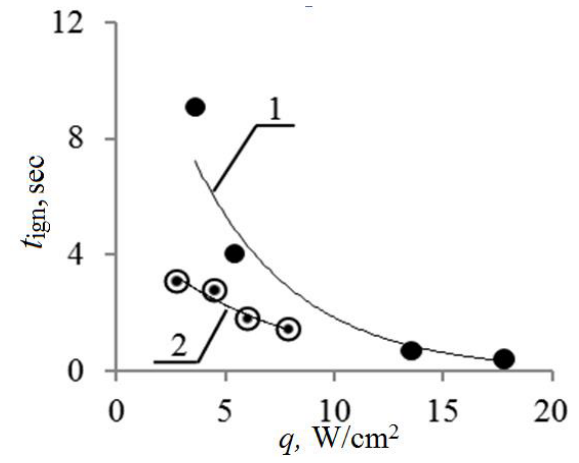

Fig. 2. The delay time of ignition during heating of constant $q_{0}(1)$ and increasing $q(2)$ heat flux.

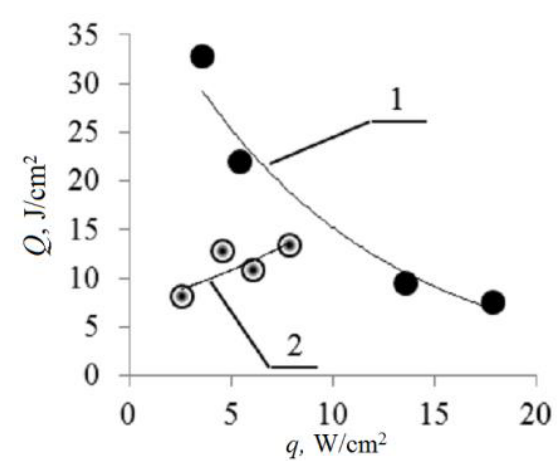

Fig. 3. The dependence of $Q$ on the density of the heat flux at heating of constant $q_{0}(1)$ and increasing $q(2)$ heat flux.

The found effect is described with the peculiarities of forming the heated layer of the condensed phase under conditions of static and dynamic regimes of heating of gun-cotton.

\section{Conclusion}

The results of experimental study of ignition of gun-cotton during the heating with increasing radiation flux in the range $(0.2 \div 22) \mathrm{W} / \mathrm{cm}^{2}$ are presented. A comparison of the delay times of the ignition at heating the samples by means of variable and constant heat flux was performed. The data obtained has shown that in the investigated range of heat flux, the flammability of gun-cotton in dynamic heating conditions is higher than in static. Physical interpretation of the obtained results requires additional research.

\section{Acknowledgments}

This work was supported by Ministry of Education and Science under the Federal Program "Research and development on priority directions of scientific-technological complex of Russia for 2014-2020”, the agreement No. 14.578.21.0034, unique identifier PNI RFMEFI57814X0034.

\section{References}

1. A. Merzhanov, A. Averson, Combust. Flame 16, 1 (1971)

2. V. Vilyunov, V. Kuznetsov, A. Skorik, Ignition of pyroxylin by high-Intensity light flux. in Gorenie i vzryv [Combustion and Explosion] (Nauka, Moscow, 1977) [in Russian]

3. L. Gusachenko, V. Zarko, A. Rychkov, COMBUST EXPLO SHOCK+ 48, 1 (2012)

4. V. Arkhipov, S. Bondarchuk, A. Korotkikh, V. Kuznetsov, A. Gromov, S. Volkov, L. Revyagin, COMBUST EXPLO SHOCK+ 48, 5 (2012)

5. R. Enaleev, V. Mateosov, K. Sinaev, B. Dinovetskiy, R. Gainutdinov, Cheboksary, Chuvash State University Publ. (1973)

6. G. Lopatina, V. Sasorov, B. Spitcyn, D. Fedoseev, Opticheskie pechi [Optical furnace] (Metallurgiya Publ., Moscow, 1969) [in Russian]

7. V. Arkhipov, V. Zarko, A. Korotkikh, V. Kuznetsov, A. Razdobreev, Method of determining the characteristics of ignition of samples high-energy materials in radiant heat flux. Patent RF № 2569641 (2015) 